\title{
David Hull
}

\author{
Peter Godfrey-Smith
}

Published online: 27 November 2010

(C) Springer Science+Business Media B.V. 2010

David Hull, who died in August, is the person most responsible for the philosophy of biology achieving the status within philosophy that it has today. He is the single figure most responsible for its flourishing. He also had profound and positive effects on the working of its internal culture and the priorities seen in research.

David was born in 1935 and grew up in the midwest of the USA. He lived in the midwest, especially the Chicago area, for almost his whole life. He did his graduate work in the early 1960s, in History and Philosophy of Science, in the visionary department at the Indiana University. He taught at just two universities, the University of Wisconsin at Milwaukee (1964-1984) and Northwestern (1984-2000). He lived openly as a gay man from the early 1960s.

When David began work, biology was often treated in the philosophy of science as an afterthought. Physics provided the subject-matter and test cases for almost all of the most influential work. David Hull, along with Michael Ruse, William Wimsatt, and some others, changed this, and the change seemed to start the moment Hull finished graduate school.

Hull's philosophical work divides into three main strands. The first is seen in his earliest published work, which appeared in the mid 1960s. This work focused on classification in biology, and the relation between classification and evolutionary theory. Hull was both wise and fortunate in choosing this as an area of interest, as classification (or "systematics") became philosophically interesting in several distinct ways during the next two decades. Biological classification had for centuries bumped into issues in metaphysics, especially concerning the concept of a species. From his earliest work Hull opposed "essentialist" approaches to classification (Hull 1965). Traditional essentialism treats species and other real kinds as having static inner natures. Like Ernst Mayr, Hull thought that a residue of essentialism had persisted through the Darwinian revolution. As Hull saw it, essentialist attitudes and

P. Godfrey-Smith $(\bowtie)$

Harvard University, Cambridge, MA, USA

e-mail: pgs@fas.harvard.edu 
methods had produced "two thousand years of stasis." A better view of classification would be more responsive to evolutionary theory. The right attitude to take to species themselves remained somewhat unfocused, however, until Michael Ghiselin, in 1975, suggested that biological species might be best seen not as kinds or classes at all, but as large scattered individuals. Hull became a vigorous defender of this idea, and developed it in philosophical detail.

Around this time biological taxonomy was also entering a period of methodological conflict. This featured the rise of "cladism," which based all classification on genealogical relations within the tree of life, and its two-way battle with "phenetic" or numerical taxonomy on one side, and the more eclectic "evolutionary" approach of Mayr and Simpson on the other. Hull did not side with one particular taxonomic school. Cladism, in its recognition of branched lineages as real entities, seems perhaps particularly suited to Hull's views about the metaphysics of evolution, but he could see strengths and weaknesses on several sides. Hull immersed himself in the culture of biological systematics and watched the field develop. In 1984-1985 he was the President of the Society of Systematic Zoology, and he was involved with the editing of its journal for many years.

Hull paid close attention to the development of networks and alliances in science, especially when these began to evolve in unexpected ways. In particular, he observed and described a split in the cladist camp in the 1980s which produced "pattern cladism," an approach which sought to sever cladist methods from assumptions about evolutionary processes. This fissure within the cladist camp became visible by looking at citations, refereeing, and other markers of influence and alliance.

The second major strand in Hull's research was an analysis of evolutionary processes, especially natural selection. As with the status of species, here Hull built on an existing view. In the 1970s Richard Dawkins, influenced especially by George Williams, gave an analysis of natural selection in terms of "replicators" and the "vehicles" they build to aid their replication. Hull modified both concepts, replacing what Dawkins backgrounded as mere "vehicles" with "interactors." He argued that the replicator and interactor roles are fundamental to any evolutionary process, and debates about the "units of selection" tend to equivocate between them.

The replicator/interactor analysis was widely accepted in the philosophy of biology for many years. It has recently been questioned (by Griesemer, myself, and Okasha), but it has undeniable resources and has been useful also to biologists writing about foundational issues. Elisabeth Lloyd extended the analysis and used it in her co-authored work with Stephen Jay Gould (1993), and Elliott Sober and David Sloan Wilson employed it in Unto Others (1998). In a late co-authored paper (2001), Hull gave a sophisticated analysis of the role played by variation and selection in different kinds of systems.

The third strand in Hull's work was his attempt to give a general account of scientific change. This was the central theme of Science as a Process (1988). This book brought together all the ideas outlined above, and extended each as it knitted them together. Hull gave an account of science which took history and sociology seriously without losing sight of what he took to be the central philosophical questions. In particular, Hull wanted to explain the success of science as an 
epistemic institution. He used the history of biological systematics as a primary source of data in the development of his view, and also sought to apply the evolutionist's mindset of "population thinking" to scientific change itself.

Hull's analysis used two methods and sets of ideas. One concerns the social structure of science and its reward system. Hull emphasized the importance of small groups, akin to biological "demes," as sources of innovation. The test-case of systematics led to him paying attention to factors that others might dismiss as minor, such as the importance of winning terminological battles. He also emphasized the cumulative character of scientific work, and the relations between different generations of workers in a given field.

The central element in this first set of ideas in Science as a Process, and perhaps the strongest in the book overall, was his analysis of credit and motivation. Scientists are curious about the world, as many people are, but what is distinctive about them is the reward system they are embedded within and usually come to embrace. Scientists want credit. They want their work to be recognized, and especially to be used by others. This involves citation. Many features of science, as Hull saw it, stem from the interaction between this reward system and its social context. Each scientist inherits the ideas and methods of their field from earlier workers. To achieve anything significant, a scientist must enter into a system of cooperation and trust. Doing good work of one's own requires using the work of others, and using their work in a way that provides real support for one's own requires giving citations. Scientists trade credit for support, in the hope that others will do the same for them. Real criticism of an idea can be expected, but it will tend to come from those invested in rival ideas or uncertain whether the idea can be safely used. Hull, like Popper, was attracted to a picture of science as a dialogue between an imaginative voice and a critical voice, but as they bear on any given topic, these voices tend to be distributed across individuals.

Hull's treatment of credit was simple and frank. Credit had also been discussed by sociologists of science. In particular, Hull built on work by Robert Merton (1973). During the time Hull was working on these ideas sociologists such as Latour and Woolgar (1979) gave much more recherche treatments of the "cycle of credit" in science. But Hull, along with Merton, saw the central features of the scientific reward system more clearly, and the importance of credit in the Hull's sense has become steadily clearer in the years since Science as a Process, with the rise of citation analysis, "H-scores," and the like.

In his treatment of the relations between the social and the epistemological, Hull took a number of things for granted. He assumed that observational evidence can show that a hypothesis is wrong, and can also provide positive support for a hypothesis. The fine-structure of the workings of evidence were not a major preoccupation for him. Instead he assumed some fairly common-sense views on these topics, trusting that sense could be made of them. But as Hull saw, these fundamentals are not enough to give us much of a story about how science works, even when epistemology is our focus. For that, we also need an account of the blend of competition and cooperation, and the roles of credit and use. These, together with basic features of evidence and testing, generate the features distinctive of science, 
especially an unusually good relationship between the motivations of the individual scientist and the epstemic goals of science as a whole.

The second set of ideas developed in Science as a Process comprise a version of evolutionary epistemology. Hull applied his replicator/interactor analysis of evolution to change within science itself; scientific ideas are competing replicators in something like the way genes are. This side of Hull's account has not, so far, been especially fruitful, but the hard-headed and empirically grounded mix of philosophy and sociology in the book has held up very well.

Hull was opinionated, and sometimes impatient, on questions of method. He disliked the artificial thought-experiments so common within philosophy. There are enough real examples to work with, he thought, and these tended to be stranger than anything we can think up. When philosophers reckon they are testing the limits of what is possible, especially in biological matters, in fact they tend to stay unhelpfully close to home.

Though Hull insisted that philosophical writing stay well-grounded within the relevant science, this did not make him a skeptic about the distinctive projects and concerns of philosophy. He did not doubt that there was definite work for philosophers to do. In this he contrasts with a naturalist in the style of Quine, who would see philosophical projects subsumed by scientific ones. Hull never envisaged such a replacement. Hull was also prepared to draw on the frameworks seen in very traditional forms of philosophy. A famous paper was called "Units of Evolution: A Metaphysical Essay" (1981) and it was indeed a metaphysical essay. In all three of the strands of research described above, Hull was willing to grapple with metaphysical questions about the entities that mattered to the analysis; he engaged in detail with the relations between classes, properties, kinds, and individuals.

As a consequence of his instincts about where and where not to press, and his close attention to the empirical side, Hull's ideas seem to age well. Papers he wrote 30 years ago remain relevant and are still read closely. The last few years have seen a revival of interest in the general notion of "individuality" in biology, for example, and Hull's work on this topic is once again the first port of call.

An integration of philosophical work with the larger context of one's life seems characteristic of many of the most successful and influential philosophers. Hull was an example. He was certainly not someone who only moved in academic circles, and he had a huge number of friends outside of philosophy. But David seemed able to bring the philosophy of science and gay urban Chicago together in a natural way. He did not seem to find any need to switch between different "modes" when he was with one group or the other. Both cultures interacted with the same man. Philosophers would often stay in his house in West Wellington Street, Chicago, for short visits or extended ones, joining the ritual of his large early dinners, with their endless supplies of wine. This continued through the 1990s, even though these were the years following the period in which David lost Dick Wellman, the great love of his life, to AIDS, and saw many other friends die awful deaths.

David Hull was extraordinarily generous in all ways. He was always ready to read drafts and give advice to young (and less young) philosophers. He always had time to listen to someone he might be able to help. He was also generous to gay men in trouble. He took many into his house during the height of the AIDS epidemic. 
These were often people whose health was in a disastrous state, and in those years AIDS patients faced an almost certain but slow death. David cared for them, though it took a toll on his spirits and stamina.

David was clear-eyed and unsentimental about human motivation. This did not seem to make him pessimistic; it just made him patient. He was frank about sex in a way startling to even to the most well-seasoned of his colleagues and friends. Similarly, when the analysis of credit and motivation in Science as a Process appeared, I think that some readers were almost a little embarrassed by its earthiness. But Hull's understanding of what motivates people enabled him to gain insights into the process of science that others had not reached. David Hull will be looked on in the future as a larger-than-life figure, which is appropriate, but he was also the most human of philosophers.

\section{References}

Hull DL (1965) The effects of essentialism on taxonomy: two thousand years of stasis. Br J Philos Sci 15:314-326 \& 16:1-18

Hull DL (1981) Units of evolution: a metaphysical essay. In: Jensen UJ, Harré R (eds) The philosophy of evolution. The Harvester Press, Brighton, England, pp 23-44

Hull DL (1988) Science as a process: an evolutionary account of the social and conceptual development of science. University of Chicago Press, Chicago

Hull DL, Glenn S, Langman R (2001) A general analysis of selection. Behav Brain Sci 24:511-573

Latour B, Woolgar S (1979) Laboratory life: the construction of scientific facts. Princeton University Press, Princeton

Lloyd EA, Gould SJ (1993) Species selection on variability. Proc Natl Acad Sci USA 90:595-599

Merton R (1973) The sociology of science: theoretical and empirical investigations. University of Chicago Press, Chicago

Sober E, Wilson DS (1998) Unto others: the evolution and psychology of unselfish behavior. Harvard University Press, Cambridge, MA 